\title{
Role of Geospatial Information for Disaster Risk Management as Exemplified in Recent Large Earthquakes in Japan
}

\author{
UNE Hiroshi ${ }^{\mathrm{a} *}$ and NAKANO Takayuki ${ }^{\mathrm{b}}$ \\ ${ }^{a}$ Geospatial Information Authority of Japan (former affiliation); hiroune@mb.infoweb.ne.jp \\ ${ }^{b}$ Geospatial Information Authority of Japan; nakano-t96fj@mlit.go.jp \\ * Corresponding author
}

\begin{abstract}
Geographic location is one of the most fundamental and indispensable information elements for us to work on disasters. For example, in the case of the Tohoku Earthquake in 2011, aerial photos taken immediately after the earthquake greatly improved the information sharing among different government offices and facilitated the rescue and recovery operations, and maps prepared after the disasters have been assisting the rapid reconstruction of the affected local communities. In addition, in the case of the Kumamoto Earthquake in 2016, up-to-date geospatial information technologies were well applied to grasp the disaster situation such as UAVs and InSAR. Advancement of web mapping technology allows us to understand the situation by overlaying various location-specific data on base maps on the web and specify the areas which the activities should be focused on. 3D modelling technology enables realistic understandings of the relationship between disaster and topography. Geospatial information technology can support the proper judgement of preparation and emergency response against disaster by the individuals and local communities through such as hazard mapping and information services using mobile devices. Thus, geospatial information technology is now more and more taking vital role for all the stages of disaster risk management and responses. Acknowledging such vital role of geospatial information for disaster reduction, Sendai Framework for Disaster Risk Reduction 2015-2030, adopted at the Third United Nations World Conference on Disaster Risk Reduction repeatedly indicates the importance of use of geospatial information technology for disaster reduction.
\end{abstract}

Keywords: disaster risk management, Tohoku Earthquake, Kumamoto Earthquake, geospatial information, Sendai Framework

\section{Role of Geospatial Information for Disaster Risk Reduction}

Geographic location is one of the most fundamental and indispensable information elements for us to work on disasters. Without geospatial information, the effect of measures or actions for disaster risk reduction would be quite limited. Resent development of geospatial information technologies has enabled decision-makers and the general public to employ geospatial information and integrate it with other information in an easy-to-use and affordable manner in every phase of the disaster management cycle, including disaster risk assessment, emergency response operations in disasters, and "build back better" recovery from disaster damage at any time and any places (Figure 1).

In Japan, the Basic Act for Disaster Countermeasures designates relevant government agencies and other organizations for disaster response operations. The Geospatial Information Authority of Japan (hereinafter "GSI"), the national organization in Japan's government for production and coordination of basic geospatial information, is included as one of them, having a legal authority providing GSI with a mandate to work on disasters. In 2012, on the basis of the lessons learned about the usefulness of geospatial information in the disaster response for the 2011 off the Pacific coast of Tohoku Earthquake (hereinafter "the Tohoku Earthquake"), the above act was amended to include a provision for maximizing the use of geospatial information in the collection and the communication of information concerning disaster prevention, reflecting larger expectation by the government for the geospatial community to provide proper geospatial information promptly.

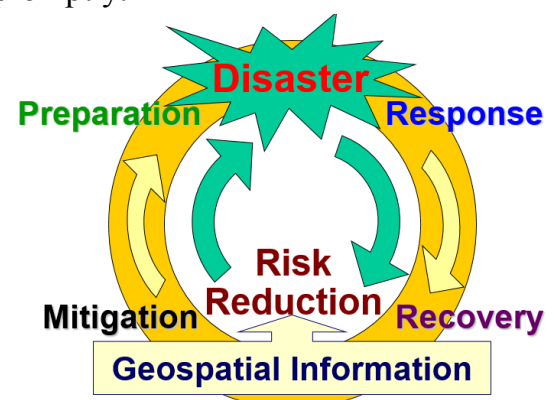

Figure 1. Disaster management cycle (originally compiled from the concept by FEMA) 


\section{The Tohoku Earthquake in 2011}

The Tohoku Earthquake took place at 2:46 PM local time on 11 March 2011. The epicenter was located about 130 $\mathrm{km}$ ESE off the Tohoku coast. Its magnitude, 9.0, was the largest observed in Japanese history and was the fourth largest in the world since 1900. In addition to terrible shaking, the main shock brought the gigantic tsunami wave more than 10 meters high with a maximum run-up height of 40 meters over a wide range of Pacific coast in the Tohoku region.

Just after the occurrence of the Tohoku Earthquake, the GSI went into emergency status and immediately set up an emergency headquarters (EHQ) to serve as the decision-making body for disaster operations. The first EHQ meeting was held at 3:10 PM, within thirty minutes of the main shock. In accordance with the decisions of the EHQ, the GSI took various actions to support the victims and damaged regions by surveying and providing geospatial information, such as distributing maps and aerial photos, observing crustal deformation and mapping inundation areas, under full collaboration with private surveying companies and related organizations. Among its efforts, three major emergency response activities were 1) provision of maps, 2) detection of ground surface movement using Global Navigation Satellite System (GNSS) control point network, and 3) aerial surveys including interpreting photos of damaged areas (Figure 2). Immediately after the Tohoku Earthquake, the GSI delivered base maps of damaged areas to relevant government offices, starting from small-scale maps sent to central government offices via the Internet or in the form of paper maps. In addition to the map data, the GSI dispatched liaison staff to those offices to provide services for preparing maps of synoptic views of the damage and recovery status for their briefings. The GSI also dispatched its staff to onsite headquarters of the government for disaster management, with map data and equipment, including computers and large-sized printers to provide paper maps in response to the needs of officials in charge of rescue and relief operations.

As for the detection of ground surface movement, the GSI made the best use of its GNSS control point network. Since 1995 the GSI has installed GEONET (GNSS Earth Observation Network System), with more than 1,200 GNSS continuous observation stations throughout the country for location reference services and detection of crustal deformation. After the main shock of the Tohoku Earthquake, the GSI made its best efforts to get initial results of ground surface movements within a few hours. Ultimately, analysis of the observed data revealed that the maximum movement was 5.3 meters in the horizontal direction and minus 1.2 meters in vertical (Figure 3 ).

In order to get a grasp of the situation with regard to damage, an aerial survey was conducted starting from the next day, covering the whole coastal region, except around the crippled nuclear reactors. The GSI possesses its own aircraft "Kunikaze 3," and a special crew team for aerial surveys. However, the damaged area to be covered was assumed to be extremely large, obviously far beyond the coverage ability of a single aircraft. In case the GSI is not available to implement emergency tasks when a disaster occurs, it has entered into an "Agreement on Emergency Photography for Disaster Occurrence" since 2005 with private surveying companies to receive assistance in conducting emergency photography efficiently. Immediately after the earthquake, the GSI decided to request the collaborative works based on this agreement to conduct coordinated emergency photography. The weather during the next few days was very cooperative, and the air crew teams were able to take aerial photos of major damaged areas on 12 and 13 March. The remaining areas were covered in subsequent survey missions by the GSI. Such a collaborative framework will be needed to function well on occasion of expected future large-scale earthquakes and tsunamis such as Nankai Trough Earthquake. In addition, the GSI is promoting development of applications for latest remote-sensing technology such as the synthetic aperture radar imaging from aerial platforms in case of disasters occurring under bad weather or at night. As a result of the emergency photography, colour aerial photographs of a total of approximately $6,900 \mathrm{~km}^{2}$ of the affected areas were taken, mostly at a scale of 1:20,000 (Figure 4). The acquired data were processed as quickly as possible, mobilizing resources through the night. Aerial photo data were delivered to major governmental organizations and uploaded to the GSI's website the next day, 14 March. The results enable comparison with photos taken before the earthquake to highlight the damage caused by the tsunamis (Figure 5).

The GSI created a "tsunami flood area overview map" to ascertain the tsunami damage situation. As the aerial photos came in, the GSI staff started working on photo interpretation of the inundated areas and compiled the results on 1:25,000 topographic maps using GIS software. Then the results were digitally copied to $1: 100,000$ scale maps for a better understanding of whole picture of the damage. These were uploaded on GSI's website (Figure $6)$. The results showed that the inundated areas came to as much as $561 \mathrm{~km}^{2}$ in total.

A few weeks after the earthquake, the GSI started two other projects for recovery of the damaged areas. The first one was a resurvey of control points. Due to the large ground displacement, it was indispensable to resurvey the control points to revise their coordinates, so that reconstruction activities would be initiated. In addition, for reconstruction planning, the GSI prepared large-scale base maps at the scale of 1:2,500 for the damaged areas. 


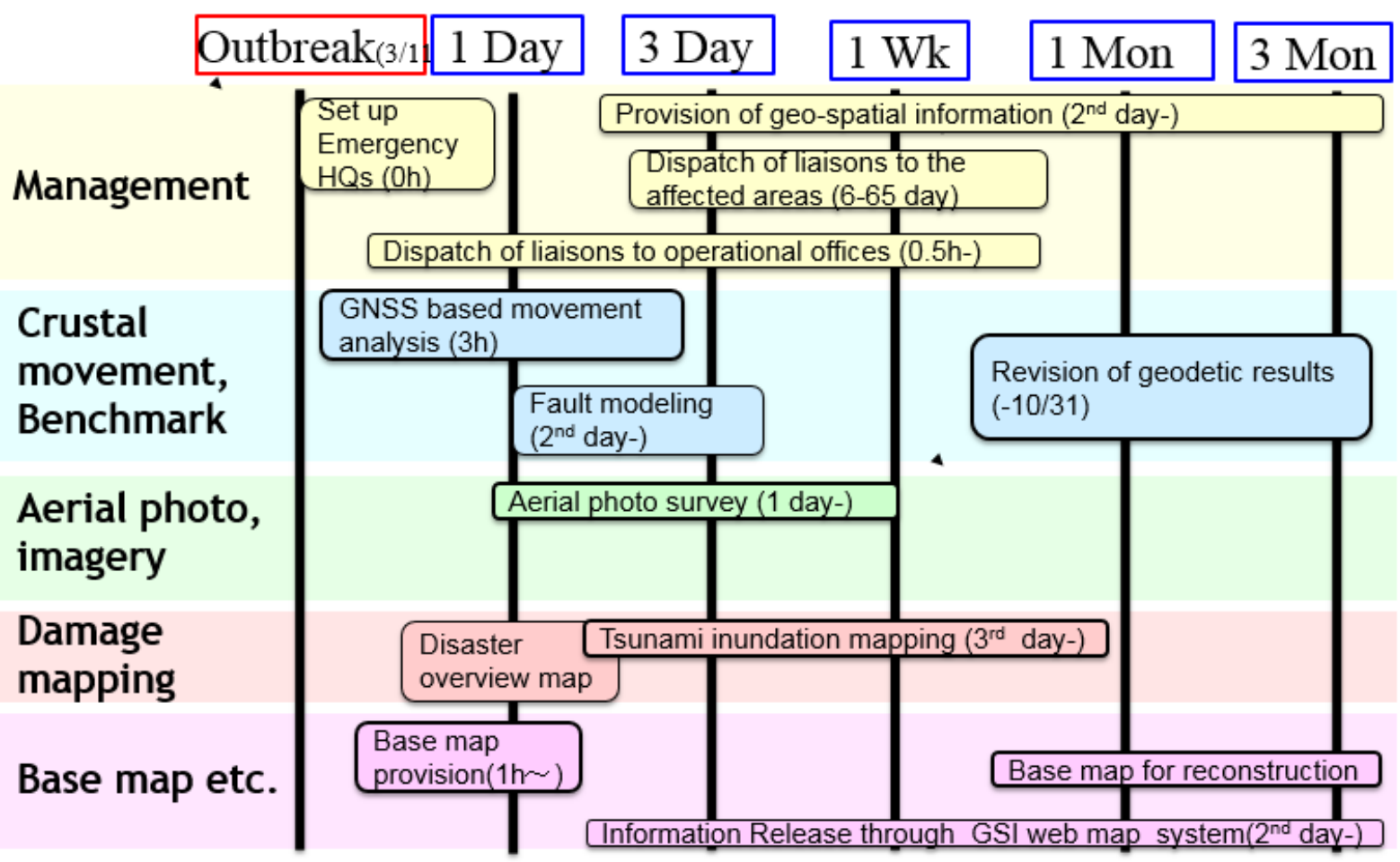

Figure 2. Emergency response activities of GSI (compiled by GSI)
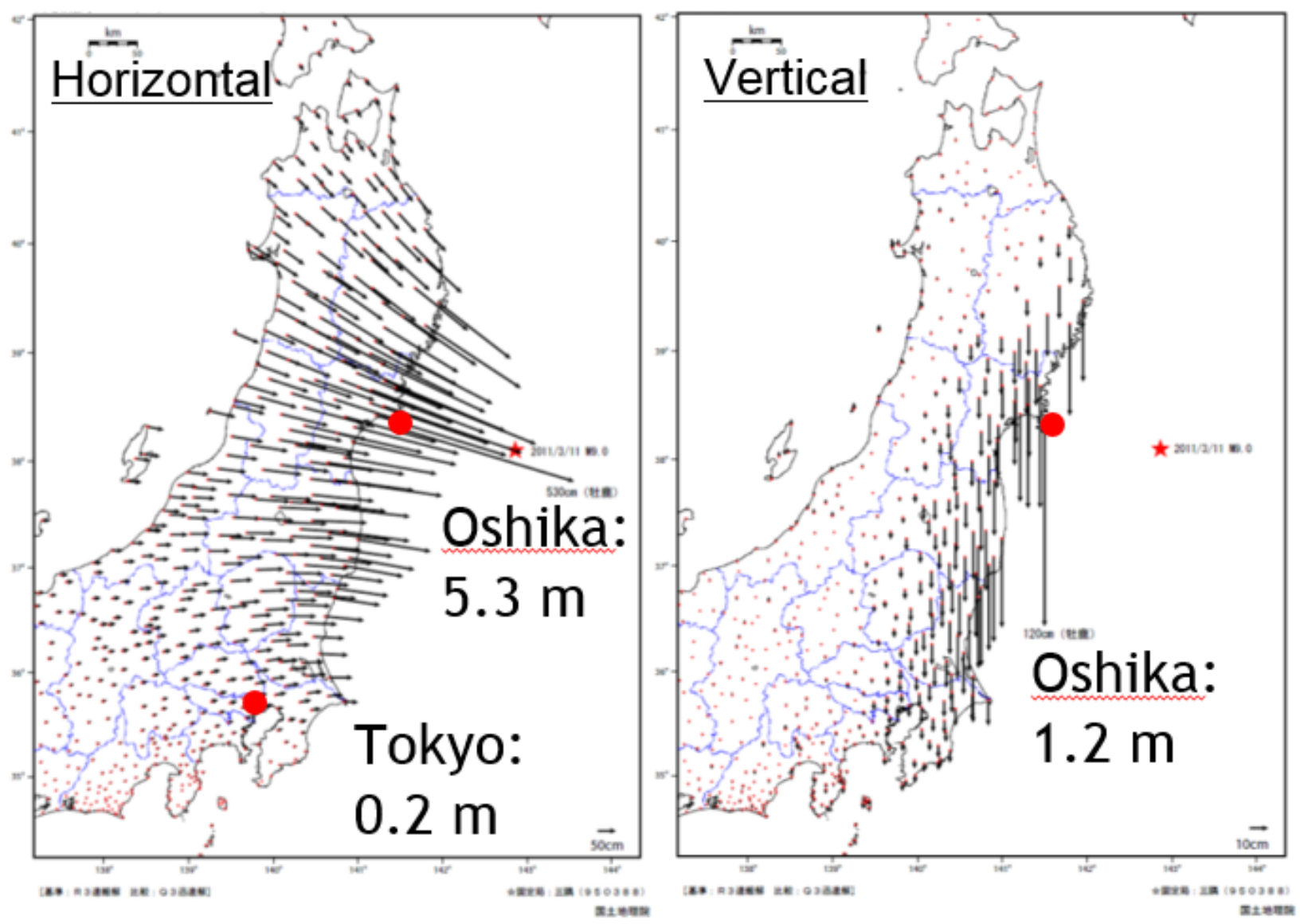

Figure 3. Ground surface movements observed by GEONET. left: horizontal deformation; right: vertical deformation (from GSI web page) 


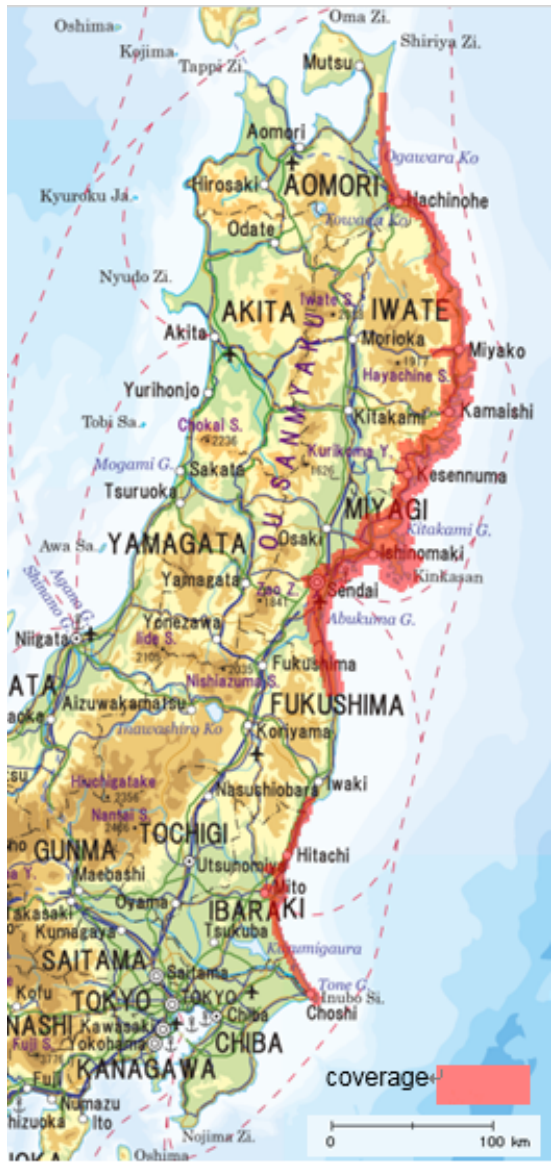

Figure 4. Areas covered by the aerial photographs (compiled by GSI)
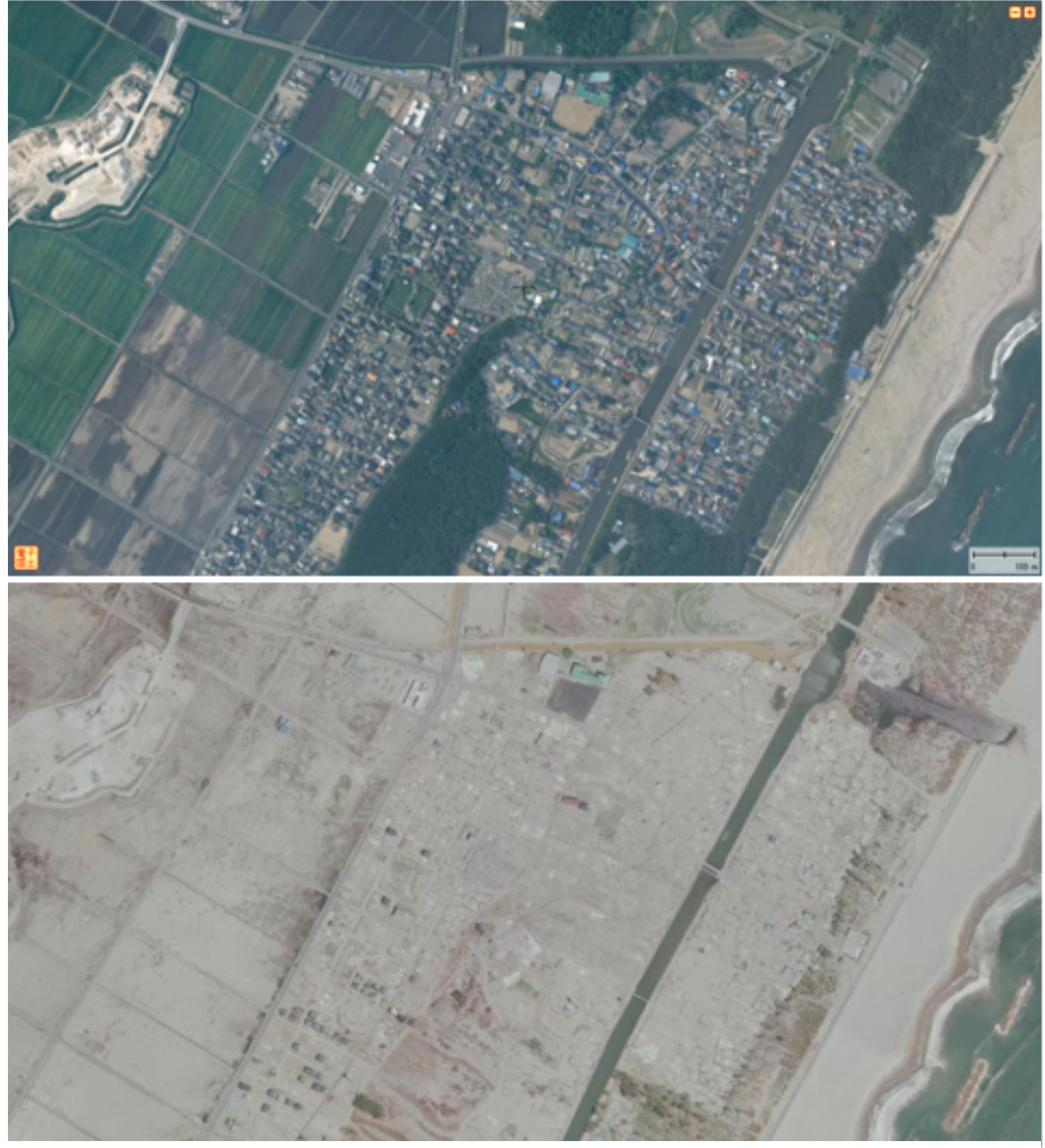

Figure 5. An example of aerial photo images of a damaged area (Natori City) taken after the Tohoku Earthquake by GSI.

upper: before the tsunami; lower: after the tsunami (from GSI web page)

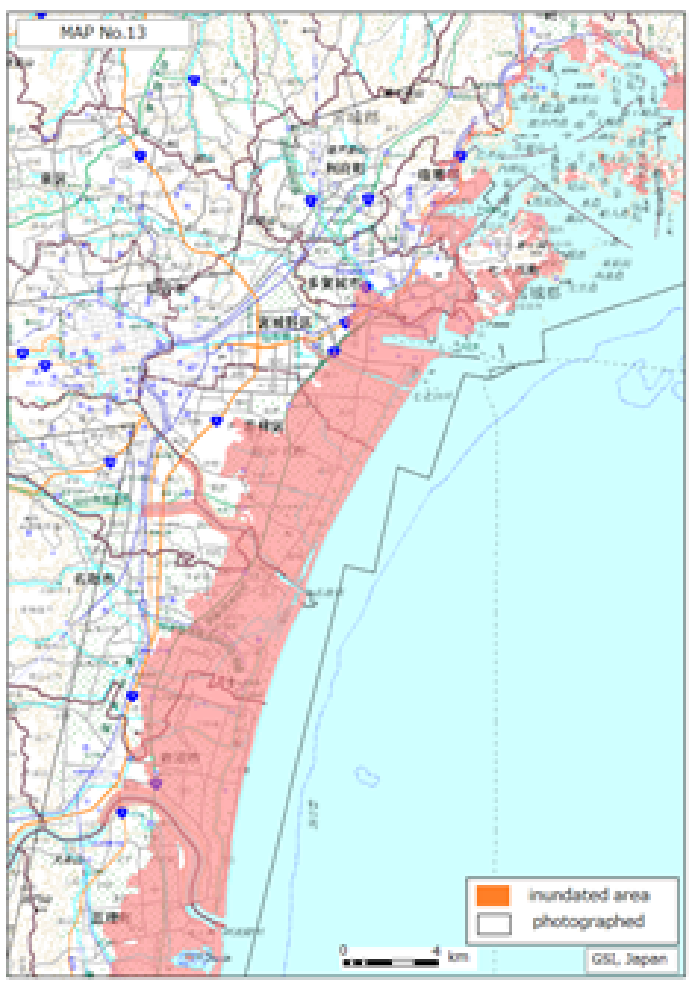

Figure6. An example of "tsunami flood area overview map" compiled on 1:25,000 topographic map (left) and digitally copied to 1:100,000 scale map (right) (from GSI web page). 
As for the resurvey of control points, about 1,900 triangulation points and about the same number of bench marks were resurveyed. For about 43,000 control points that were not directly resurveyed, coordinate correction parameters were provided, and revised coordinates were calculated. In addition, since the horizontal and vertical origins of the country's geodetic coordinate system located in Tokyo were displaced, their coordinates were also revised. This whole process was completed in less than eight months after the earthquake and contributed significantly to the recovery process.

\section{The Kumamoto Earthquake in $\mathbf{2 0 1 6}$}

Then, five years has passed when the western part of our archipelago was attacked by another severe ground shaking. The Kumamoto Earthquake sequence started from a magnitude 6.5 earthquake which occurred on April 14 at night, followed by a magnitude 7.3 earthquake which occurred on April 16 at early morning. Damages caused by the earthquake include more than 200 human casualties, up to 3,000 people injured, and 9,000 buildings were completely destroyed.

As the initial stage, aerial photos were taken in three periods: (1) next day of the first M.6.5 earthquake occurred on April 14; (2) the day of the main-shock M.7.3 on April 16, and (3) April 19 and 20 (Figure 7). Fresh aerial photos are essential for understanding the emergency status. For example, we found some scars on the upper part of the slope through our photo interpretation and informed the danger to local authority (Figure 8).

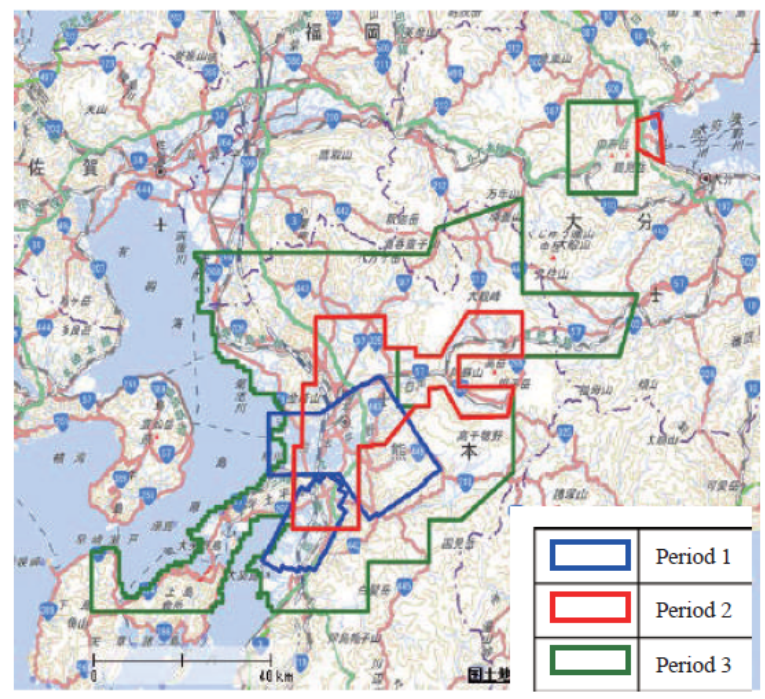

Figure 7. Areas of aerial photos (compiled by GSI)
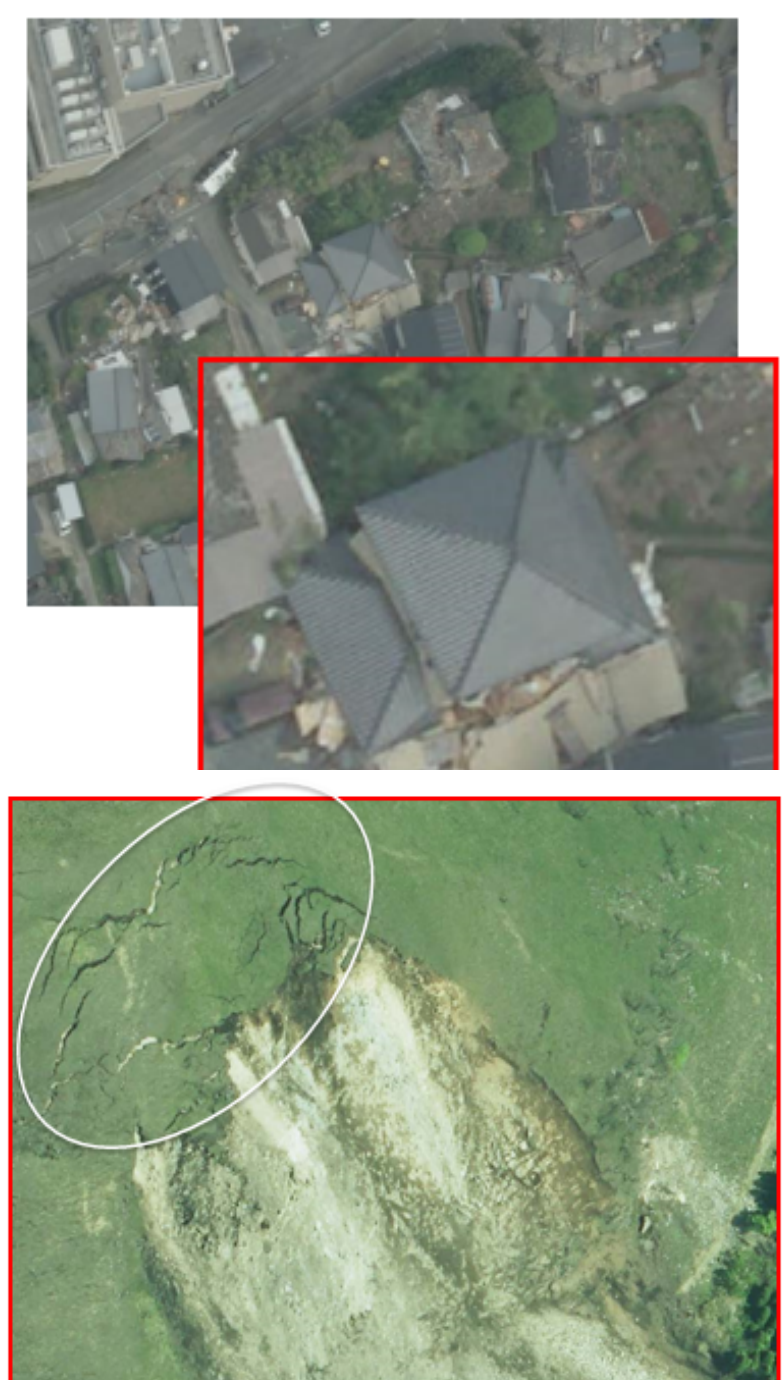

Figure 8. Examples of aerial photos.

upper: collapsed buildings, lower: cracks on the slope (from GSI web page)

SAR interferometry (InSAR) using the data from the Advanced Land Observation Satellite 2 (ALOS-2), launched and operated by Japan Aerospace Exploration Agency (JAXA) provided spatial distribution of the detailed co-seismic deformations caused by the Kumamoto Earthquake. Displacements over $2 \mathrm{~m}$ were clearly seen after the main shock. This information was utilized in understanding and estimating the mechanism of the earthquake source faults (Figure 9). 


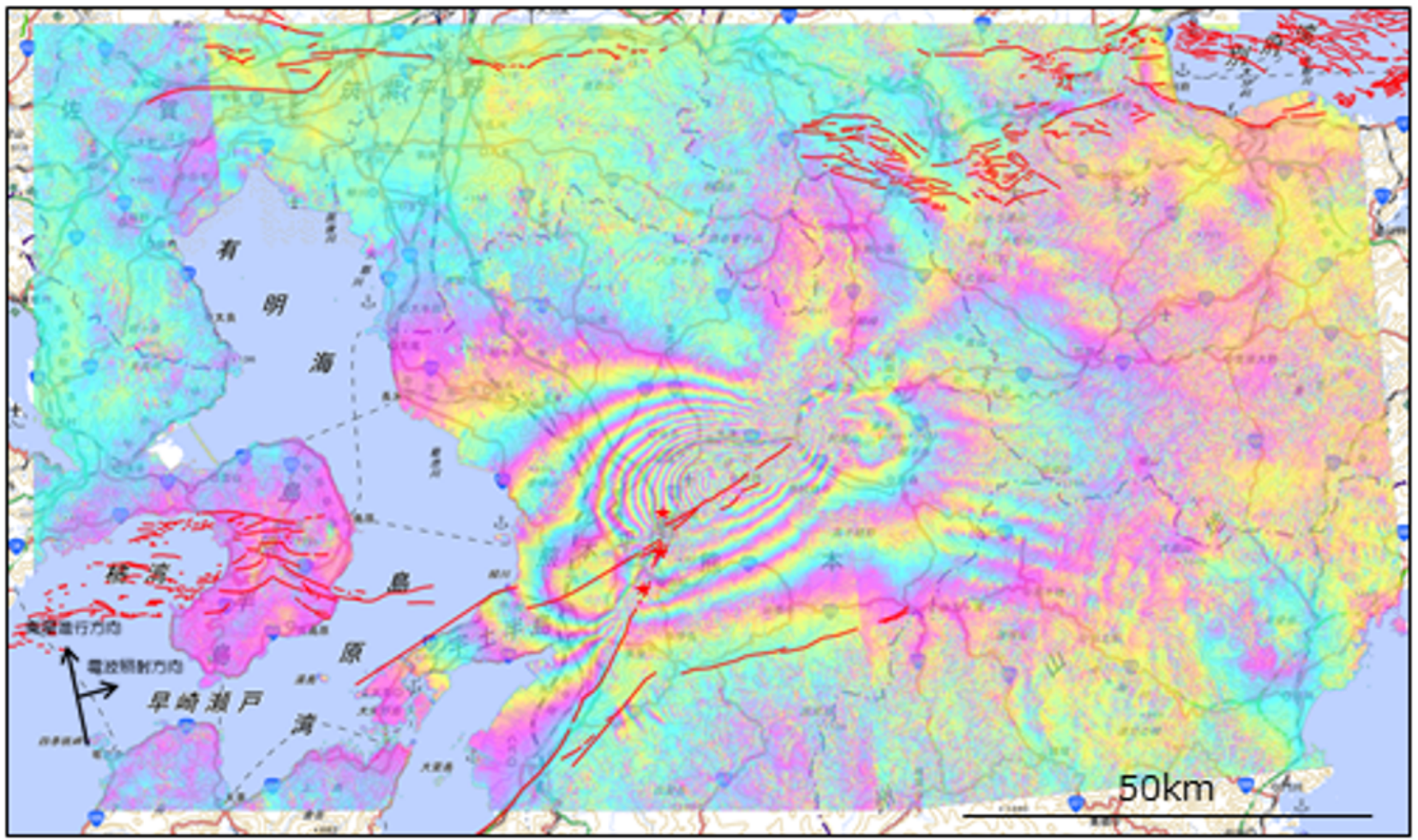

Figure 9. SAR interferogramme (from GSI web page)

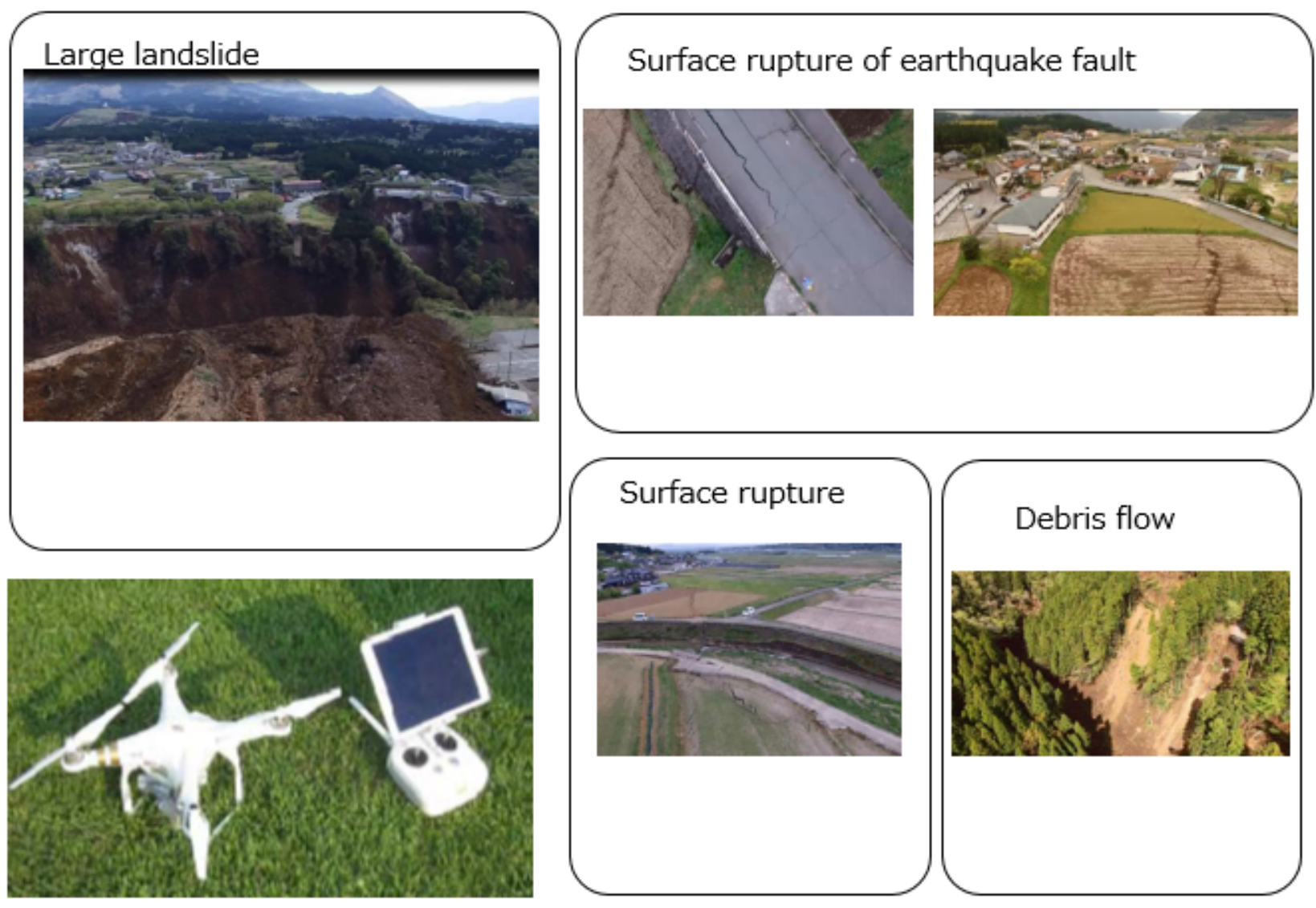

Figure 10. UAV and its results (compiled by GSI) 


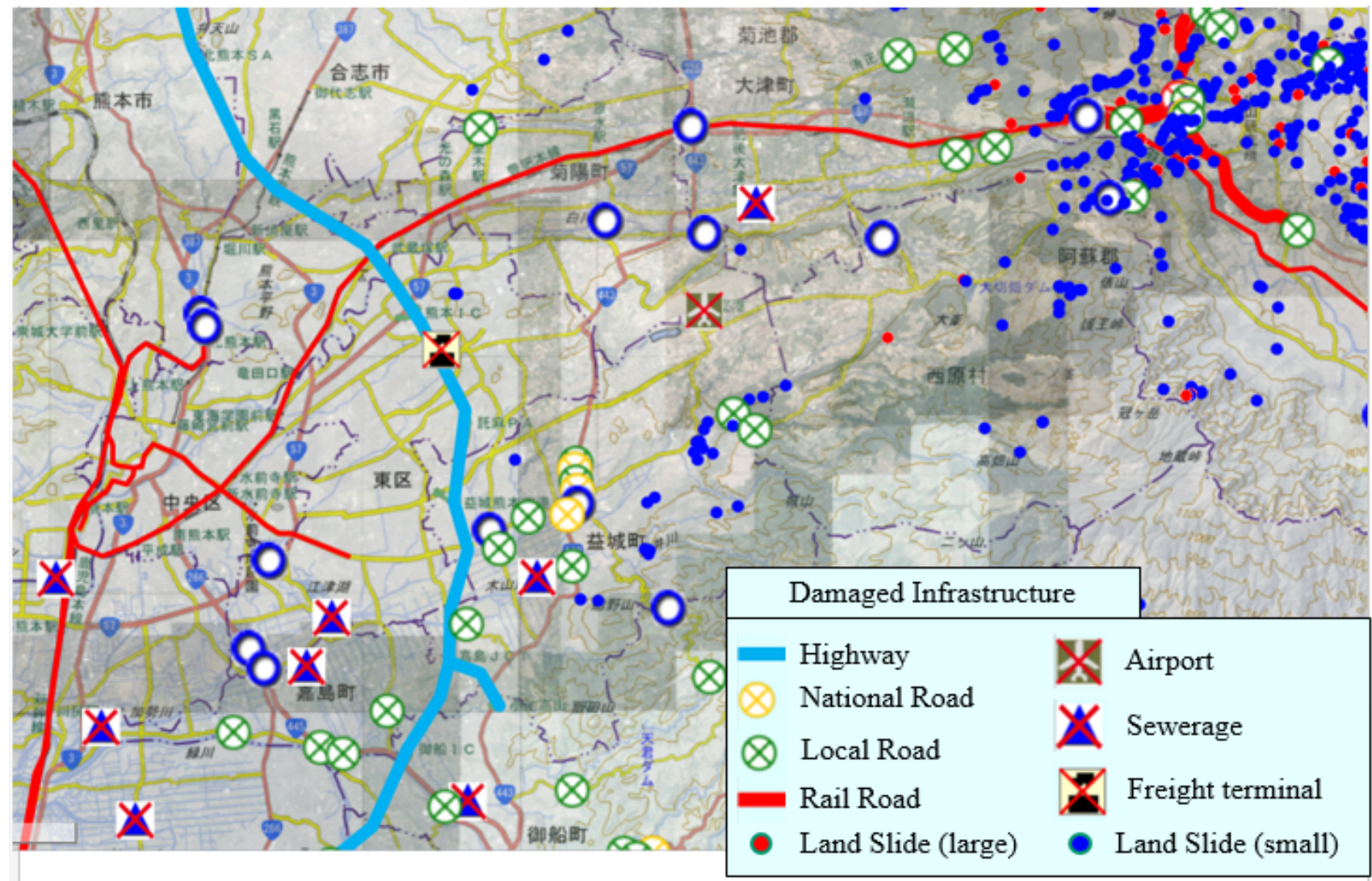

Figure 11. Integration of damage information on GSI Maps (compiled by GSI).

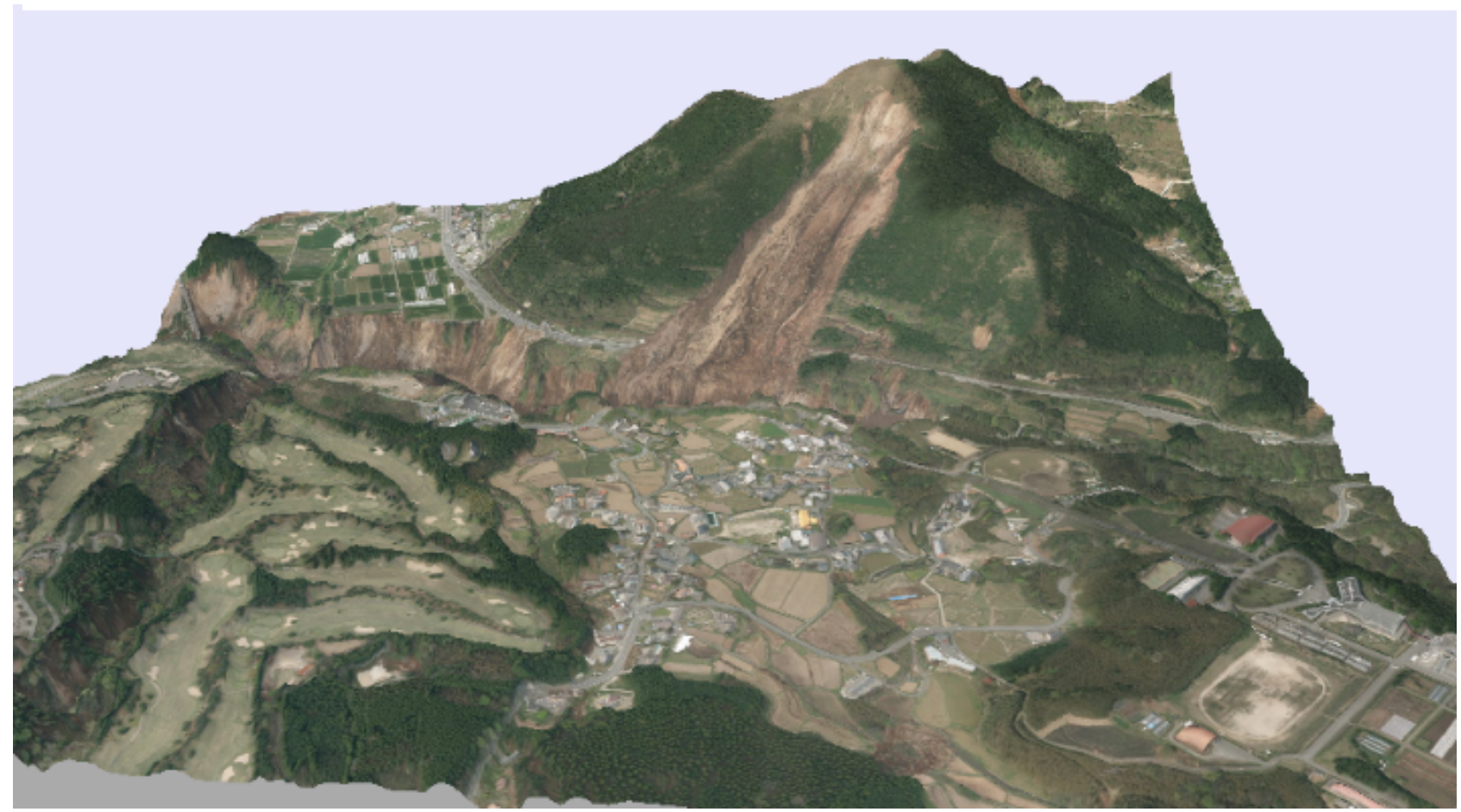

Figure 12. 3D presentation of a landslide. 3D presentation function is automatically facilitated in GSI Maps (from GSI web page). 
Another newly introduced technology to grasp the disaster situation is an unmanned aerial vehicle (UAV). It provided high resolution aerial images taken from low altitude. It provided clear images of such as surface ruptures of the earthquake fault and large landslides (Figure 10).

All such information were provided overlain on "GSI Maps". GSI Maps are web-based maps provided by GSI. Various geospatial information from GSI such as topographic maps, aerial photographs, altitudes, land conditions and disaster information can be overlaid in the display. It allows us to understand the situation by overlaying various location-specific data on a base map on the web, and specify the areas which the activities should be focused on (Fig 11).

In addition, GSI Maps has a function to display 3D maps. 3D image enables realistic understandings of the relationship between disaster and topography (Figure 12).

\section{Recent innovation of geospatial information for disaster risk reduction}

Thanks to recent development of geospatial information technology, geospatial information has become more essential for disaster response activities.

Advancement of web mapping technology allows us to understand the situation by overlaying various locationspecific data on a base map on the web, and specify the areas which the activities should be focused on. Image processing software applying SfM (Structure from Motion) and MVS (Multi-View Stereo) theory has brought the innovation of acquisition methods of disaster information. It enables to create seamless orthographic image from oblique photos, which means that, in order to take vertical aerial photographs for grasping disaster situation, we no longer have to wait for the weather recovery after flooding caused by heavy rain or the end of volcanic activities after the eruption. 3D modelling technology enables realistic understandings of the relationship between disaster and topography.

Geospatial information technology can support the proper judgement of preparation and emergency response against disaster by the individuals and local communities through such as hazard mapping and information services using mobile devices. For instance, mobile phone applications to assist the evacuation of residents and network analysis system of evacuation routes as the risk communication tool among local community have been rapidly popularizing.

Thus, geospatial information technology, the result of geography and cartography, is now more and more taking vital role for all the stages of disaster risk management and responses. Acknowledging such vital role of geospatial information for disaster reduction, Sendai Framework for Disaster Risk Reduction 2015-2030, adopted at the Third United Nations World Conference on Disaster Risk Reduction, held in March 2015 in Sendai, Miyagi, Japan, repeatedly indicates the importance of use of geospatial information technology for disaster reduction.

\section{Acknowledgement}

ALOS-2 data were provided by the Earthquake Working Group, under a cooperative research contract with JAXA. The ownership of ALOS-2 data belongs to JAXA.

\section{References}

Une, H. and Koarai, M. (2014). Disaster Responses of the Geospatial Information Authority of Japan: Special Focus on Tsunami Inundation Mapping. Global Environmental Research, 18(1), 9-18. 